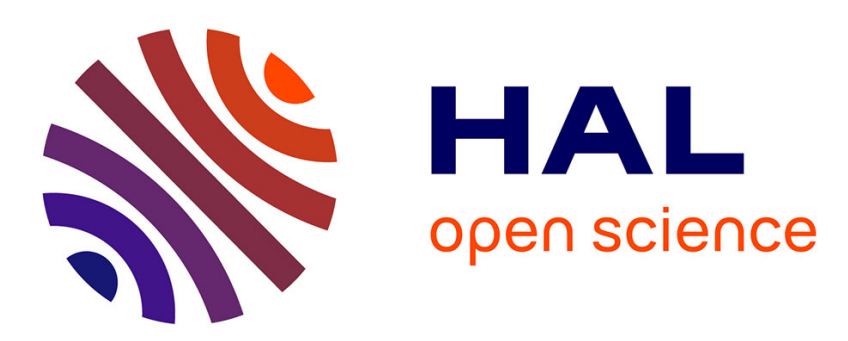

\title{
Mid-infrared supercontinuum generation seeded by geometrical parametric instabilities amplified in TDFA
}

Geoffroy Granger, Yann Leventoux, Alessandro Tonello, Stefan Wabnitz, Vincent Couderc, Sébastien Février

\section{- To cite this version:}

Geoffroy Granger, Yann Leventoux, Alessandro Tonello, Stefan Wabnitz, Vincent Couderc, et al.. Midinfrared supercontinuum generation seeded by geometrical parametric instabilities amplified in TDFA. Specialty Optical Fibers, 2020, Washington, France. pp.SoTu3H.6, 10.1364/SOF.2020.SoTu3H.6 . hal-03003388

\section{HAL Id: hal-03003388 \\ https://hal.science/hal-03003388}

Submitted on 16 Nov 2020

HAL is a multi-disciplinary open access archive for the deposit and dissemination of scientific research documents, whether they are published or not. The documents may come from teaching and research institutions in France or abroad, or from public or private research centers.
L'archive ouverte pluridisciplinaire HAL, est destinée au dépôt et à la diffusion de documents scientifiques de niveau recherche, publiés ou non, émanant des établissements d'enseignement et de recherche français ou étrangers, des laboratoires publics ou privés. 


\title{
Mid-infrared supercontinuum generation seeded by geometrical parametric instabilities amplified in TDFA
}

\author{
Geoffroy Granger ${ }^{1}$, Yann Leventoux ${ }^{1}$, Alessandro Tonello ${ }^{1}$, Stefan Wabnitz $^{2}$, Vincent Couderc ${ }^{1}$, and \\ Sebastien Fevrier ${ }^{1}$ \\ ${ }^{1}$ Université de Limoges, XLIM, UMR CNRS 7252, 123 Av. A. Thomas, 87060 Limoges, France \\ ${ }^{2}$ Dipartimento di Ingegneria dell'Informazione, Elettronica e Telecomunicazioni, Sapienza University of \\ Rome, Via Eudossiana 18, 00184 Rome, Italy \\ sebastien.fevrier@unilim.fr
}

\begin{abstract}
We demonstrate thulium-doped fiber amplification of sub-nanosecond pulses generated at $1870 \mathrm{~nm}$ by exploiting spatiotemporal nonlinear dynamics in graded-index multimode fibers. The microjoule pulses at $1870 \mathrm{~nm}$ trigger supercontinuum generation in $\mathrm{InF}_{3}$ fiber. (C 2020 The Author(s)
\end{abstract}

\section{Introduction}

High-energy transform-limited pulses with tens to hundreds of picosecond duration in the near to mid-infrared are particularly interesting for many applications such as polymer or semi-conductor micro-processing, or to act as a pump for mid-infrared supercontinuum generation. However, these temporal characteristics are difficult to reach because of the Q-switching process, which limits the pulse generation in the nanosecond scale. Whereas modelocking techniques deliver short pulses in the picosecond/femtosecond domains.

In this communication, we present a novel approach to generate high-energy sub-nanosecond pulses, by exploiting complex spatiotemporal nonlinear dynamics in graded index (GRIN) multimode fibers. Because of their particular core refractive index profile, the intermodal beating in GRIN fibers gives birth to a longitudinal modulation of the multimode field, producing a periodic self-imaging [1,2] of the Gaussian input beam. When combined with the Kerr nonlinearity, the self-imaging process leads to a periodic nonlinear refractive index modulation, which allows for quasi-phase-matching of parametric processes, both in the spatial and in the frequency domains. Thus, spatial selfcleaning and geometric parametric instability may be observed, and generate either a spatial beam reorganization [3] or a series of sidebands [4], which are detuned by more than $100 \mathrm{THz}$ from the pump. It has also been demonstrated that this nonlinear frequency conversion regime is accompanied by a strong temporal shortening of pulses emerging from the sidebands, while keeping unchanged the initial repetition rate of the pump source. Moreover, the spectral detuning, which is determined by the optogeometrical characteristics of the fiber, can be easily matched to the spectral gain of several ions used for amplification in optical fibers [5].

Here, we describe how to optimize the refractive index profile of a GRIN fiber and the parameters of the pump laser, in order to drive the emission of sub-nanosecond pulses in the thulium-doped fiber amplifier (TDFA) emission band. Next we demonstrate the efficient pulse amplification of these spectral emissions in a core-pumped TDFA. We also illustrate the strong applicative potential of our amplified source, by generating a mid-infrared supercontinuum spanning from 1800 to $3500 \mathrm{~nm}$ in fluoride fiber.

\section{Experimental results}

In Fig. 1 we depict the experimental setup to produce sub-nanosecond pulses at $1870 \mathrm{~nm}$ from a GRIN multimode fiber, and to amplify the pulse energy to the microjoule level in a TDFA. 
L1

$50 \mathrm{~mm}$

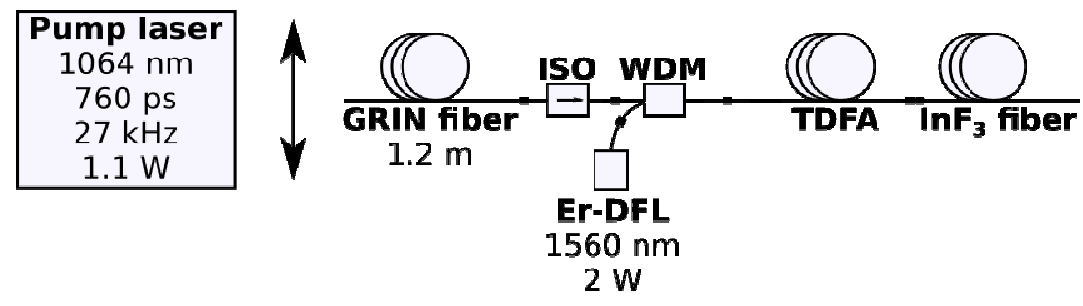

Fig. 1. Schematic of the laser setup

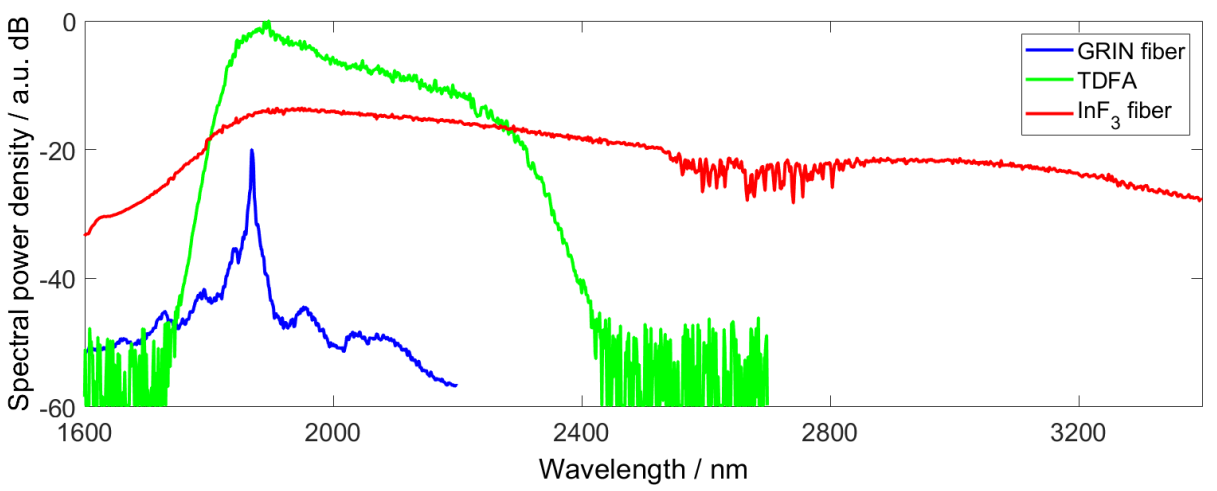

Fig. 2. Measured spectra.

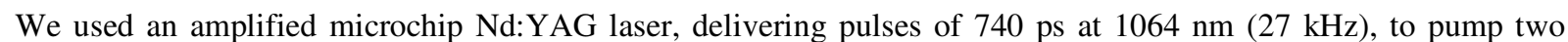
different GRIN multimode fibers with $52 \mu \mathrm{m}$ and $62.5 \mu \mathrm{m}$ core diameters, respectively. The pump beam triggers the generation of sidebands at $2070 \mathrm{~nm}$ in the $52 \mu \mathrm{m}$ GRIN fiber, and at $1870 \mathrm{~nm}$ in the $62.5 \mu \mathrm{m}$ GRIN fiber. In the following, we restrict our analysis to the generation of sidebands in $62.5 \mu \mathrm{m}$ GRIN fiber, because the $1870 \mathrm{~nm}$ line is well-suited to seed a core-pumped TDFA. The amplifier is based on a single-mode, large core area TDF, pumped at $1560 \mathrm{~nm}$ by a cw Erbium-doped fiber laser delivering up to $2 \mathrm{~W}$. The pump and seed beams are multiplexed through a 1560/1900 wavelength division multiplexer. Amplification of the generated sidebands at $1870 \mathrm{~nm}$ yields pulses with several microjoules of energy. Finally, we demonstrate the suitability of our new approach to midinfrared supercontinuum generation, by launching the amplified pulses in an $\mathrm{InF}_{3}$ fiber (Le Verre Fluoré). The spectrum spans up to $3400 \mathrm{~nm}$, which is the limit of the optical spectrum analyser (Yokogawa).

S.W. acknowledges support from the European Research Council (ERC) under the European Union's Horizon 2020 research and innovation program (grant No. 740355).

\section{References}

[1] X. Zhu, A. Schülzgen, H. Li, L. Li, L. Han, J. V. Moloney, and N. Peyghambarian, "Detailed investigation of self-imaging in large core multimode optical fibers for application in fiber lasers and amplifiers," Opt. Express 16, 16632-16645 (2008).

[2] G.P. Agrawal, "Self-imaging in multimode graded-index fibers and its impact on the nonlinear phenomena," Opt. Fiber Technol. 50, 309-316 (2019).

[3] K. Krupa, A. Tonello, A. Barthélémy, V. Couderc, B. M. Shalaby, A. Bendahmane, G. Millot, and S. Wabnitz, "Observation of Geometric Parametric Instability Induced by the Periodic Spatial Self-Imaging of Multimode Waves“, Phys. Rev. Lett. 116, 183901 (2016).

[4] K. Krupa et al., "Spatial beam self-cleaning in multimode fibres,” Nat. Photonics 11, 237-241 (2017).

[5] K. Krupa, A. Tonello, V. Couderc, A. Barthélémy, G. Millot, D. Modotto, and S. Wabnitz, "Spatiotemporal light-beam compression from nonlinear mode coupling," Phys. Rev. A 97, 043836 (2018). 